\title{
EDITORIAL
}

\section{COVID-19 Vaccine Uptake in Pakistan: No Time to Err}

\author{
Dr. Sarosh Saleem
}

Doi: doi.org/10.53685/jshmdc.v2i1.20

The COVID vaccination drive started in Pakistan earlier this year. The population most at risk of the COVID infection, the healthcare workers was the first ones to be offered vaccination in Pakistan. A step-wise approach was adopted to offer vaccination to the whole population. At the moment, everyone above 18 years of age has access to COVID 19 vaccine in Pakistan. Apart from that, several companies are offering various approved COVID vaccines at cost. Hence, it seems that most of the population in Pakistan should be vaccinated by end of the year and life may come back to normal. As good as it sounds; the reality seems far from this. The total population of Pakistan is more than 20.7 million according to the 2017 national census ${ }^{1}$. Only 3,566,547 people have been vaccinated in Pakistan, to date ${ }^{2}$. This means that only $1.72 \%$ of the whole population has been vaccinated so far. A month after the vaccination for frontline health care workers started, only 197,000 doses of the COVID 19 vaccine had been administered ${ }^{3}$. Our current vaccination rate puts us at the lowest bit of the countries that have COVID 19 vaccination data ${ }^{4}$.

An estimate in 2014 shows that Pakistan has more than 430,000 registered health care workers ${ }^{5}$. There are 117 medical and 59 dental colleges, both private and public, registered by Pakistan Medical Council (PMC) ${ }^{5}$. Nearly 20,000 students graduate from these medical and dental colleges, every year. Approximately 12,000 nursing professionals graduate each year ${ }^{6}$. This population was among the first ones to receive vaccination in Pakistan and yet they have shown significantly low rates of vaccination. The population of one the most educated professionals in our country hesitated to take the vaccine offered. There were several reasons described. The explanations ranged from, 'lack of information about vaccines', and 'fear of side effects' to 'doubtful efficacy' and 'history of COVID infection'7. There may be other reasons that need to be explored and addressed. Several myths and conspiracy theories have been circulating on social media regarding COVID 19 disease and vaccine. This has at least busted a general myth of vaccine hesitancy only by less literate populations of Pakistan. But the situation is alarming. With more than 20,000 mortalities and nearly one million cases since February 2020, the economic impact has been enormous. Children and students have been out of school for nearly 16 months. Many have lost their jobs and loved ones. It is high time for the public and particularly the health care community to volunteer for vaccination. This alone will not suffice; the government and institutions should nudge the health care workers and community at large to take up this responsibility of protecting themselves and others.

The moral responsibility of health care professionals is to follow the principles of 'beneficence' and 'nonmaleficence'. The benefit of the larger population is at stake. Pakistan does have precedence over mandating a crucial vaccination. Polio vaccine has been made mandatory for every child in Pakistan ${ }^{8}$. Even though a mandate may be too harsh for individual autonomy, nudges from government and organizations would at least make individuals consider notions of solidarity and social responsibility. There are several measures taken to protect the spread of COVID 19 infection but hand hygiene, wearing masks, and keeping social distance have practical limitations. The cumulative impact of the COVID 19 pandemic has been on social, mental, physical, financial, and intellectual levels. We all want our lives back and most of all, the families of health care 
professionals do not wish to live with the fears they have been facing for more than a year now. Hence health care professionals and institutions should be the brand ambassadors for vaccination drive. This is essential to motivate a large number of our population to take up vaccination. This is the only hope.

\section{References:}

1. Pakistan Bureau of Statistics. Population Census. 2017. Available from: https://www.pbs.gov.pk/content/populationcensus (Accessed 10.06.2021)

2. NCOC (National Command Operation Center). Vaccine Statistics. 2021 [cited 23.06.2021]. Available from: https://ncoc.gov.pk/covid-vaccination-en.php (accessed 23.06.2021)

3. Hashim A. Vaccine hesitancy in Pakistan heightens risk of COVID resurgence [Internet]. Aljazeera.com. 2021. [cited 01.06.2021] Available from: https://www.aljazeera.com/news/2021/3/5/in-pakistan-vaccine-hesitancyheightens-risk-of-covid-19-resurge (accessed 23.06.2021)

4. Mathieu E, Ritchie H, Ortiz-Ospina E, Roser M, Hasell J, Appel C, et al. A global database of COVID-19 vaccinations. Nat Hum Behav. 2021. doi: 10.1038/s41562-021-01122-8.

5. Yahya M. PMC - Pakistan Medical Commission. 2021. Available from: http://www.pmc.gov.pk/ (accessed 01.06.2021)

6. Pakistan Nursing Council. List of PNC Recognized Institutions for Diploma Program, Degree Program and Post Basic Diploma Program. 2021. Available from: https://pnc.org.pk/PNC_Recognized_Institutes.htm (accessed 01.06.2021)

7. Malik A, Malik J, Ishaq U. Acceptance of COVID-19 Vaccine in Pakistan Among Health Care Workers. medRxiv. 2021; Available from: https://www.medrxiv.org/content/early/2021/02/24/2021.02.23.21252271 (accessed 23.06.2021)

8. The Punjab Vaccination Ordinance, 1958. An Ordinance to consolidate and amend the law relating to vaccination in the Province of the Punjab. 2021. Available from: http://punjablaws.gov.pk/laws/95.html (accessed 01.06.2021)

\section{Corresponding Author:}

Dr. Sarosh Saleem

Assistant Professor

Department of Bioethics

Shalamar Medical \& Dental College, Lahore.

Email address: sarosh.saleem@ sihs.org.pk 